\title{
Female sexual function and depressive symptoms among premenopausal females on hemodialysis
}

\section{Original Article}

\author{
Yasser S. Nasrallah, Radwa E. M. Marie, Moustafa M. K. Eyada
}

Department of Andrology, Dermatology and Venereology, Suez Canal University, Ismailia

Egypt.

\begin{abstract}
Background Premenopausal female Patient treated with hemodialysis experience various physical and emotional symptoms that impair their quality of life. Studies demonstrating sexual dysfunction (SD) among those patients are limited and there is no consensus about the relation of SD with the prevalence of depressive symptoms among them.

Objective: The study aims to understand the association of hemodialysis with SD as well as depression and to examine whether SD is a risk factor of depression among those patients.

Patients and Methods: 82 premenopausal sexually active married females on hemodialysis were enrolled in the study. History taking, general and genital examination were performed. Sexual function was evaluated using the Female Sexual Function Index (FSFI) questionnaire. Depressive symptomswere assessed using the Center for Epidemiologic StudiesDepression (CESD) scale. SD was studied as an independent predictor of depression.

Results: OF all enrolled patients, 56 (68.3\%) had SD while 25 (30.5\%) had depression. Patients with SD had significant higher mean age, illiteracy rate, mean duration of marriage and mean duration of dialysis. Patients with SD had significant higher depressive symptoms in comparison to patients without SD.

Conclusion: SD is highly prevalent in premenopausal females undergoing hemodialysis. Age, Literacy, duration of marriage, and duration of dialysis might be risk factors of SD among them. SD might be a predictor of depression among those patients.
\end{abstract}

Key Words: Depressive symptoms, female sexual dysfunction, haemodialysis.

Received: 24 July 2019, Accepted: 28 October 2019

Corresponding Author: Yasser S. Nasrallah, Department of Andrology, Dermatology and Venereology, Faculty of Medicine, Suez Canal University, Ismailia, Egypt, Tel.: 002-01016932575, E-mail: dryassersalem75@gmail.com

ISSN: 2090-6048, June 2019 Vol. 9, No. 2

\section{INTRODUCTION}

End-stage renal disease (ESRD) is defined as chronic renal disease in which kidneys function is irreversibly less than $15 \%$ of normal. It is usually treated with long term hemodialysis as a lifesaving measure ${ }^{[1]}$. Hemodialysis is usually associated with physical and psychosocial impairment that adversely affects quality of life ${ }^{[2]}$. Fatigue, pain, depression, itching and sleep difficulty are common symptoms among those patients ${ }^{[3]}$. SD is also highly prevalent. It has been estimated to affect nearly $84 \%$ of women on hemodialysis ${ }^{[4]}$.

SD includes a heterogeneous group of disorders that are characterized by significant disturbance in person's ability to respond sexually or to experience sexual pleasure ${ }^{[5]}$. According to the Diagnostic and Statistical Manual of Mental Disorders (DSM V) ${ }^{[6]}$, female SD includes sexual interest/arousal disorder, female orgasmic disorder, genitopelvic pain/penetration disorder (vaginismus and dyspareuniain DSM IV $)^{[7]}$ and substance/medicationinduced SD.
Female sexual interest/arousal disorder is characterized by a lack of, or significantly reduced, sexual interest and/or arousal. Female orgasmic disorder is defined as persistent or recurrent delay in, or absence of, or reduced intensity of, orgasm following a normal excitement phase ${ }^{[7]}$.

Genito-pelvic pain/penetration disorder is defined as persistent or recurrent difficulties with vaginal penetration during intercourse. Patients experience marked fear or anxiety about vulvovaginal or pelvic pain in anticipation of, during or as a result of vaginal penetration ${ }^{[6]}$.

Many factors lead to SD in ESRD female patients, including anemia, mineral disturbances, bone disorders, changes in hypothalamic-pituitary function, autonomic neuropathy ${ }^{[8]}$, psychosocial factors (depression, anxiety, poor self-confidence, marital discord, body image, fear of morbidity and death, loss of employment, social withdrawal and financial difficulties), medications (antihypertensives, antidepressant, and antihistaminics), and comorbid illness (diabetes mellitus, cardiovascular disease, malnutrition) ${ }^{[9]}$.

Depression affects $20-25 \%$ of patients on hemodialysis 
and negatively affects quality of life and treatment adherence ${ }^{[10,11]}$. Females on hemodialysis are more affected by depression than men.12SD is not usually taken as a risk factor for depression ${ }^{[13]}$

This study aimed to investigate the association of hemodialysis with female SD as well as depression and to examine whether SD is a risk factor of depression among those patients.

\section{PATIENTS AND METHODS}

This is a cross-sectional study that was conducted at Dermatology, Andrology, Nephrology and Hemodialysis Departments, Suez Canal University Hospitals in Ismailiain about 3 to 4 months duration in accordance with the guidelines of the Helsinki Declaration.

The study population included 82 premenopausal sexually active married females on hemodialysis who admitted at Nephrology and Hemodialysis Department, Suez Canal University Hospitals. An informed consent was taken from all participantsafter receiving full information on the study setup and purpose. The study was approved by the local Institutional Review board and the Research Ethical Committee. Patients with a past history of any psychiatric illness prior to hemodialysis, or with marital conflicts or refused to participate were excluded from the study. Patients were subjected tofull history taking, physical examination (general and genital). Theywere interviewed using the questionnaires: FSFI table 1 for SD and CESD for depressive symptoms ${ }^{[14,15]}$.

Table 1: The female sexual function index (FSFI) questionnaire score

\begin{tabular}{|c|c|c|c|c|c|c|}
\hline Domain & Questions & Score range & Factor & Minimum score & Maximum score & Score \\
\hline Desire & 1,2 & $1-5$ & 0.6 & 1.2 & 6.0 & \\
\hline Arousal & $3,4,5,6$ & $0-5$ & 0.3 & 0 & 6.0 & \\
\hline Lubrication & $7,8,9,10$ & $0-5$ & 0.3 & 0 & 6.0 & \\
\hline Orgasm & $11,12,13$ & $0-5$ & 0.4 & 0 & 6.0 & \\
\hline Satisfaction & $14,15,16$ & 0 (or 1$)-5$ & 0.4 & 0.8 & 6.0 & \\
\hline Pain & $17,18,19$ & $0-5$ & 0.4 & 0 & 6.0 & \\
\hline \multicolumn{4}{|c|}{ Full Scale Score Range } & 2.0 & 36.0 & \\
\hline
\end{tabular}

\section{RESULTS}

\section{Demographic and clinical data:}

The age of patients ranged from 22 to $48 y$ years with a mean age of $30.68 \pm 8.6$ years. Thirty one patients $(37.8 \%)$ were illiterate, $16(19.5 \%)$ had secondary education, 35 $(42.7 \%)$ were highly educated. Twenty patients $(24.4 \%)$ were employed. Duration of marriage ranged from 2 to 28 years with a mean duration of $18.5 \pm 8.4$ years. Duration of dialysis ranged from 0.5 to 13 years with a mean duration of $1.4 \pm 0.99$ years.

FSFI scores, CES-D scores and prevalence of SD and depressive symptoms among patients:

Total FSFI ranged from 19.4-31.4 with a mean of 26.42 \pm 3.55 . Depression score (CES-D) ranged from 6-21 with a mean of $10.05 \pm 3.8$ (Table 2). Fifty-six patients $(68.3 \%)$ had SD, while 25 patients $(30.5 \%)$ had depression (Table 3). The most affected sexual function was arousal $(100 \%)$, followed by lubrication (97.6\%), and then desire $(90.2 \%)$. The least affected sexual function was pain $(29.3 \%)$. Satisfaction-related sexual dysfunction was present in $65.9 \%$ of patients (Table 2).

\section{Relation between the socio-demographic characteristics of premenopausal females undergoing hemodialysis and the presence of SD:}

Patients with SD had statistically significant higher mean age, higher illiteracy rate, higher mean duration of marriage, and higher mean duration of dialysis in comparison to women without SD (Table 4). The risk of SD was approximately 4-folds higher in illiterate women, 2-folds higher in unemployed women, 5-folds higher in women with duration of marriage $\geq 15$ years and 3 -folds higher in women with duration of dialysis $\geq 2$ years (Table 5).

Relation between SD and the presence of depressive symptoms measured by CES-D among premenopausal women undergoing hemodialysis:

Patients with SD had significant higher mean depressive score (11.7 versus 9.1, respectively) $(p<0.01)$ in comparison to patients without SD. In addition, Patients with SD had significant higher prevalence of depressive symptoms compared to patients without SD (41.1\% versus $7.7 \%$, respectively) $(p<0.01)$ (Table 6$)$. 
Table 2: Mean scores of Female Sexual Function Index (FSFI) and Center for Epidemiologic Studies-Depression (CES-D) among premenopausal females on hemodialysis $(n=82)$

\begin{tabular}{|c|c|c|c|c|}
\hline \multirow{2}{*}{ Variables } & \multicolumn{3}{|c|}{ Total population $(\mathrm{n}=82)$} & \multirow{2}{*}{$\begin{array}{c}\text { Normal domain } \\
\text { scores }\end{array}$} \\
\hline & Mean \pm SD & Range & Dysfunction rate & \\
\hline Desire & $3.1 \pm 0.79$ & $1-4$ & $90.2 \%$ & $\geq 4.28$ \\
\hline Arousal & $3.6 \pm 0.81$ & $2.4-4.8$ & $100.0 \%$ & $\geq 5.08$ \\
\hline Lubrication & $4.6 \pm 0.78$ & $3.0-5.4$ & $97.6 \%$ & $\geq 5.45$ \\
\hline Orgasm & $4.58 \pm 0.84$ & $3-6$ & $61.0 \%$ & $\geq 5.05$ \\
\hline Satisfaction & $5.02 \pm 0.47$ & $4.4-6.0$ & $65.9 \%$ & $\geq 5.04$ \\
\hline Pain & $5.47 \pm 0.90$ & $3-6$ & $29.3 \%$ & $\geq 5.51$ \\
\hline Total FSFI & $26.42 \pm 3.55$ & $19.4-31.4$ & $68.3 \%$ & $\geq 26.55$ \\
\hline Depression score (CES-D) & $10.05 \pm 3.8$ & $6-21$ & $30.5 \%$ & $<15.0$ \\
\hline
\end{tabular}

Table 3: Prevalence of SD and depressive symptoms among premenopausal females on hemodialysis $(n=82)$

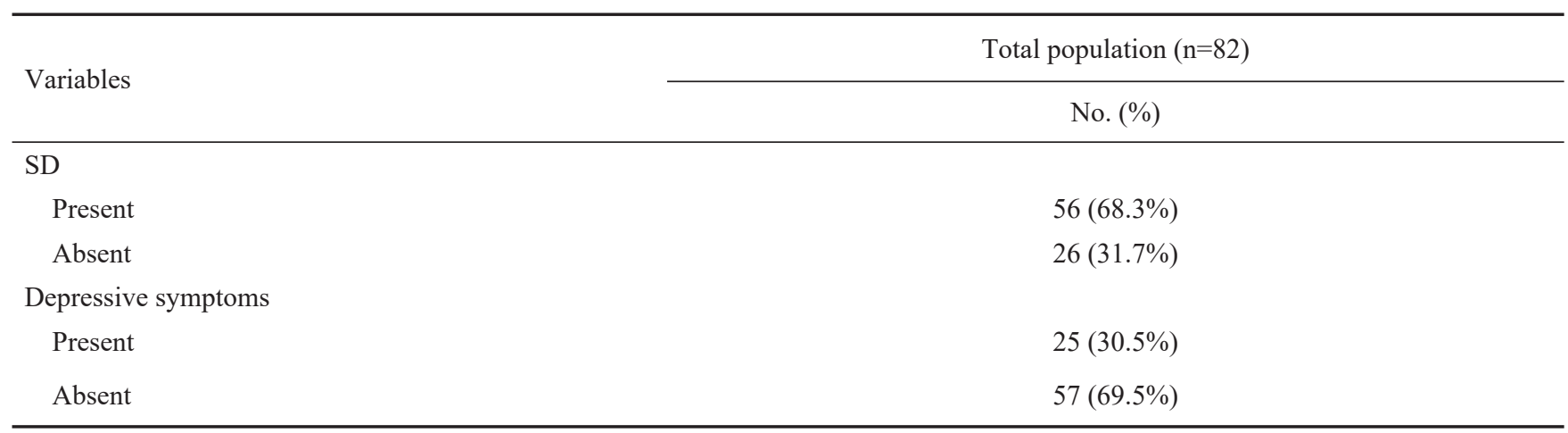

Table 4: Relation between socio-demographic characteristics of premenopausal females on hemodialysis and the presence of SD

\begin{tabular}{|c|c|c|c|c|}
\hline Variables & No SD $(n=26)$ & $\mathrm{SD}(\mathrm{n}=56)$ & Used test & $p$-value \\
\hline \multicolumn{5}{|l|}{ Age (years) } \\
\hline Mean \pm SD & $35.4 \pm 8.2$ & $44.2 \pm 6.2$ & $\mathrm{t}=3.6$ & $0.001^{* *}$ \\
\hline \multicolumn{5}{|c|}{ Educational attainment, n (\%) } \\
\hline Illiterate & $5(19.2 \%)$ & $26(46.5 \%)$ & $\mathrm{FE}$ & $0.05^{*}$ \\
\hline Secondary education & $5(19.2 \%)$ & $11(19.6 \%)$ & $\mathrm{FE}$ & 0.63 \\
\hline High education & $16(61.5 \%)$ & $19(33.9 \%)$ & $\chi^{2 Y}=2.01$ & 0.16 \\
\hline \multicolumn{5}{|l|}{ Employment, n (\%) } \\
\hline Unemployed & $17(65.4 \%)$ & $45(80.4 \%)$ & \multirow{2}{*}{$\mathrm{FE}$} & \multirow{2}{*}{0.48} \\
\hline Employed & $9(34.6 \%)$ & $11(19.6 \%)$ & & \\
\hline \multicolumn{5}{|c|}{ Duration of marriage (years) } \\
\hline Mean \pm SD & $15.2 \pm 7.7$ & $24.3 \pm 6.2$ & $\mathrm{t}=3.9$ & $0.0004^{* *}$ \\
\hline \multicolumn{5}{|c|}{ Duration of dialysis (years) } \\
\hline Mean \pm SD & $1.15 \pm 0.83$ & $1.92 \pm 1.1$ & $\mathrm{t}=2.5$ & $0.015^{*}$ \\
\hline
\end{tabular}


Table 5: Socio-demographic factors affecting sexual function in premenopausal females on hemodialysis presented by multivariate-odds ratios (OR) and 95\% confident interval (CI)

\begin{tabular}{lcc}
\hline Variables & OR & $95 \%$ CI \\
\hline Non-educated (illiterate) versus educated & 3.7 & $0.90-15.0$ \\
Unemployed versus employed & 2.1 & $0.47-9.5$ \\
Duration of marriage $\geq 15$ years & 4.8 & $1.1-21.0$ \\
Duration of dialysis $\geq 2$ years & 3.1 & $0.82-11.8$ \\
\hline
\end{tabular}

Table 6: Relation between SD and the presence of depressive symptoms measured by CES-D among premenopausal females on hemodialysis:

\begin{tabular}{|c|c|c|c|c|c|c|c|c|}
\hline \multirow{2}{*}{ Variables } & \multicolumn{2}{|c|}{ No SD $(n=26)$} & \multicolumn{2}{|c|}{$\mathrm{SD}(\mathrm{n}=56)$} & \multirow{2}{*}{ OR } & \multirow{2}{*}{$95 \% \mathrm{CI}$} & \multirow{2}{*}{ Used test } & \multirow{2}{*}{$P$-value } \\
\hline & Mean & $\mathrm{SD}$ & Mean & SD & & & & \\
\hline CES-D & 9.1 & 2.7 & 11.7 & 4.9 & - & - & & $0.0026^{* *}$ \\
\hline \multicolumn{9}{|c|}{ Depressive symptoms } \\
\hline Present & \multicolumn{2}{|c|}{$2(7.7 \%)$} & \multicolumn{2}{|c|}{$23(41.1 \%)$} & \multirow{2}{*}{8.4} & \multirow{2}{*}{$1.8-38.9$} & \multirow{2}{*}{$\chi^{2}=7.8$} & \multirow{2}{*}{$0.005^{* *}$} \\
\hline Absent & & & & & & & & \\
\hline
\end{tabular}

\section{DISCUSSION}

Hemodialysis, although life-preserving, is associated with poor survival, high symptom burden, and impaired quality of life. SD contributes to the symptom burden of ESRD. This study aims to emphasize the association between hemodialysis, female SD and depressive symptoms and to highlight the role of SD as a risk factor of depression among females on hemodialysis.

In this study, the prevalence of SD among premenopausal women undergoing hemodialysis was $68.3 \%$. In agreement with our study; Basok et al. ${ }^{[16]}$ revealed that the prevalence of SD was $66.7 \%$ in hemodialysis patients and $81 \%$ in peritoneal dialysis patients.

In similar prospect, Filocamo et al. ${ }^{[17]}$ reported absence of active sexual life among 23 out of 39 (59\%) females on hemodialysis for more than 6 months (age ranged from 18 to 45 years). In addition, Navaneethan et al. ${ }^{[8]}$ demonstrated that $55 \%$ of sexually active women on hemodialysis experience SD.

A higher prevalence was reported by Seethala et al. ${ }^{[19]}$ The prevalence of SD among 37 hemodialysis married female patients was 27 (73\%). Santos et al. also demonstrate that the prevalence of SD among women on HD is nearly $80 \%$ which worsens their quality of life especially the physical aspects ${ }^{[19]}$.

Mor et al. ${ }^{[20]}$ noted that $81 \%$ of women on hemodialysis (mean age $=64)$ had sexual inactivity. The study demonstrated that themain reasons reported by patientsfor lack of sexual activity were lack of apartner (39\%) and lack of interest (43\%). Actual sexual difficulties were reported by only $2 \%$ of patients. The study assessed also women's perception of sexual inactivity. 64\%of women with sexual inactivity reported moderate to high satisfaction with their sexual lives; on the other hand, only $19 \%$ of women reported moderateto high dissatisfaction with their sexual lives. Thus, regarding this study, the lack of sexual activitydidnot seemto be amajor problem for women on hemodialysis ${ }^{[20]}$.

A meta-analysis conducted by Strippoli et al. ${ }^{[4]}$ suggests that $84 \%$ of women on dialysis have SD (defined as FSFI of $\geq 18$ ). The study emphasized that age and the presence of a potential sexual partner are strong determinants of sexual activity.

This study reported that patients with SD had significant higher mean age. Similarly, Basok et al. ${ }^{[16]}$ reported that on logistic regression analysis, age and health status were significantly associated with female SD. In addition, a significant negative correlation was found between total FSFI score and age $(r=-0.288, p=0.002)$ in a study conducted by Yazici et al. ${ }^{[21]}$.

The study revealed that the most affected sexual function was arousal $(100 \%)$, followed by lubrication $(97.6 \%)$, and then desire (90.2\%). The least affected sexual function was pain $(29.3 \%) .65 .9 \%$ of patients had satisfaction-related SD. 
Similarly, the most commonly observed sexual problems in women in the general population are lack of interest in sex, inability to orgasm, and reduced desire ${ }^{[22]}$.

In this study, the prevalence of depressive symptoms among premenopausal women on hemodialysis was $30.5 \%$. Women with SD had significant higher mean depressive score and higher prevalence of depressive symptoms in comparison to women without SD.

In agreement, Seethala et al. ${ }^{[19]}$ found that $36 \%$ of the female patients on dialysis had depressive symptoms. Female SD was associated with age, depressive symptoms, menopause, low educational attainment and diabetes. Among patients with depressive disorder, scores were correlated with the sexual arousal, pain, and satisfaction FSFI subscales.19In the same direction, Navaneethan et al. ${ }^{[18]}$ reported that depressive symptoms are strongly associated with SD. Theofilou investigated the relation of depressive and anxiety symptoms to sexual functioning among hemodialysis and peritoneal dialysis patients. The study found that sexual functions were related negatively to depression and anxiety ${ }^{[23]}$. Similarly, Santos et al. reported that SD is an underestimated cause of depression that should be included in the treatment plan of depression ${ }^{[24]}$.

Yazici et $a .^{[21]}$ found that the rate of depression among female patients on hemodialysis was $43.8 \%$. A significant negative correlation between total FSFI score and Beck Depression Index (BDI) score $(\mathrm{r}=-0.471, p<0.001)$ was also fond. Peng et al. ${ }^{[25]}$ reported that BDI score was the independent factor of dysfunction in each sexual functional dimension. A recent study assessed the prevalence and correlates of each domain of sexual functioningin women undergoing hemodialysis. The study reported that the presence of depression was associated with worselubrication and pain $\operatorname{scores}^{[26]}$.

\section{CONCLUSION}

Hemodialysis affects sexual function and satisfaction in female patients.SD is a precipitating factor of depression among those patients. Thus, a precise evaluation of SD will promote positive patient outcomes and compliance with treatment plans.

\section{CONFLICT OF INTEREST}

There are no conflicts of interest.

\section{REFERENCES}

1. Abouna GM. Organ shortage crisis: Problems and possible solutions. Transplant Proc 2008; 40:34-38.
2. Kimmel PL, Patel SS. Quality of life in patients with chronic kidney disease: Focus on end-stage renal disease treated with hemodialysis. SeminNephrol 2006; 26: 68-79.

3. Weisbord SD, Fried LF, Arnold RM,Fine MJ, Levenson DJ, Peterson RA, Switzer GE. Prevalence, severity, and importance of physical and emotional symptoms in chronic hemodialysis patients. J Am SocNephrol 2005; 16: 2487-2494.

4. Strippoli GF, Vecchio M, Palmer S, et al. Collaborative Depression and Sexual Dysfunction (CDS) in Hemodialysis Working Group: Sexual dysfunction in women with ESRD requiring hemodialysis. Clin J Am SocNephrol 2012; 7: 974 981.

5. Sadock BJ, Kaplan HI, Sadock VA. Kaplan and Sadock comprehensive textbook of psychiatry. 11th ed. Philadelphia: Lippincott Williams and Wilkins; 2009; 287-294.

6. American Psychiatric Association .Diagnostic and statistical manual of mental disorders. 5. Washington, DC: American Psychiatric Association; 2013.

7. American Psychiatric Association .Diagnostic and statistical manual of mental disorders. 4. Washington, DC: American Psychiatric Association; 1994.

8. Anantharaman P, Schmidt RJ. Sexual function in chronic kidney disease.Adv Chronic Kidney Dis 2007; 14:119- 125 .

9. Finkelstein F, Shirani S, Wuerth D, Finkelstein SH. Therapy insight: Sexual dysfunction in patients with chronic kidney disease. Nat ClinPractNephrol 2007; 3:200-207.

10. Akman B, Uyar M, Afsar B, Sezer S, Ozdemir FN, Haberal M. Adherence, depression and quality of life in patients on a renal transplantation waiting list. TransplInt 2007; 20:682-687.

11. Santos PR. Depression and quality of life of hemodialysis patients living in poor region of Brazil. Rev Bras Psiquiatr 2011; 33:332-337.

12. Lopes GB, Matos CM, Leite EB, et al. Depression as a potential explanation for gender differences in health-related quality of life among patients on maintenance hemodialysis. Nephron ClinPract 2010; 115: $35-40$

13. Arau'jo SMHA, Bruin VMS, Daher EF, Almeida $\mathrm{GH}$, Medeiros CAM, Bruin PFC. Risk factors for depressive symptoms in a large population on chronic 
hemodialysis. IntUrolNephrol. 2012; 44:1229-1235.

14. Smith W, Beadle K, Shuster EJ.The impact of a group psychoeducational appointment on women with sexual dysfunction. Am J ObstetGynecol 2008;198:697.

15. Anis TH, Gheit SA, Saied HS, Akherbash SA.Arabic translation of Female Sexual Function Index and validation in an Egyptian population. J Sex Med 2011; 12:3370-8.

16. Basok E, Atsu N, Rifaioglu M, Kantarci G,Yildirim A, Tokuc R. Assessment of female sexual function and quality of life in predialysis, peritoneal dialysis, hemodialysis, and renal transplant patients. IntUrolNephrol 2009; 41: 473-481.

17. Filocamo M, Zanazzi M, Li Marzi V, et al. Sexual dysfunction in women during dialysis and after renal transplantation. J Sex Med 2009; 6: 3125-3131.

18. Navaneethan S, Vecchio M, Johnson $\mathrm{D}$, et al. Prevalence and correlates of self-reported sexual dysfunction in CKD: A meta-analysis of observational studies. Am J Kidney Dis 2010; 56: $670-685$

19. Seethala S, Hess R, Bossola M, Unruh ML, Weisbord SD. Sexual dysfunction in women receiving maintenance dialysis. HemodialInt 2010; 14:55-60.

20. MorM, SevickM, Shields A, Green J,Palevsky P,
FineM,Weisbord S. Sexual function, activity, and satisfaction among women receivingmaintenance hemodialysis. Clin J Am SocNephrol 2013; 9: 128-134.

21. Yazici R, Altintepe L, Guney I, et al. Female sexual dysfunction in peritoneal dialysis and hemodialysis patients. Ren Fail 2009; 31: 360-364.

22. Laumann EO, Nicolosi A, Glasser DB, Paik A, Gingell C, Moreira E, Wang T. Sexual problems among women andmen aged 40-80 y: Prevalence and correlates identified in theGlobal Study of Sexual Attitudes and Behaviors. Int J ImpotRes 2005;17:39-57.

23. Theofilou PA. Sexual functioning in chronic kidney disease: the association with depression and anxiety. HemodialInt 2012; 16(1):76-81.

24. Santos PR, Capote JR Jr, Cavalcanti JU, Vieira CB,Rocha AR, Apolônio NA, de Oliveira EB.Sexual dysfunction predicts depression among women on hemodialysis.IntUrolNephrol 2013;45(6):1741-6.

25. Peng Y, Chiang C, Kao T. Sexual dysfunction in female hemodialysis patients: A multicenter study. Kidney Int 2005; 68: 760-765.

26. Saglimbene V, Natale $\mathrm{P}$, Palmer $\mathrm{S}$, et al. The prevalence and correlates of low sexual functioning in women on hemodialysis: A multinational, crosssectional study.PLoS One 2017;12(6):e0179511. 